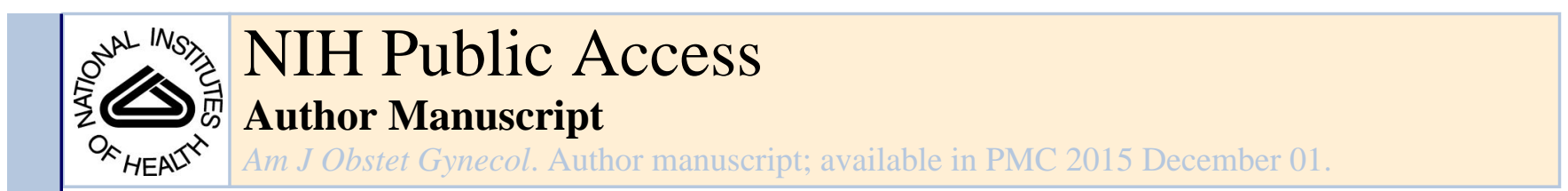

Published in final edited form as:

Am J Obstet Gynecol. 2014 December ; 211(6): 635.e1-635.e7. doi:10.1016/j.ajog.2014.06.044.

\title{
Evidence of mononuclear cell preactivation in the fasting state in polycystic ovary syndrome
}

\author{
Frank GONZÁLEZ, MD, \\ Dept. of Obstetrics and Gynecology, Indiana University School of Medicine, Indianapolis, IN \\ 46202
}

John P. KIRWAN, PhD,

Dept. of PathoBiology, Lerner Research Institute, Cleveland Clinic, Cleveland, $\mathrm{OH} 44195$

Neal S. ROTE, PhD, and

Dept. of Reproductive Biology, Case Western Reserve University School of Medicine, Cleveland,

$\mathrm{OH} 44109$

Judi MINIUM, BS

Dept. of Reproductive Biology, Case Western Reserve University School of Medicine, Cleveland, $\mathrm{OH} 44109$

\section{Abstract}

OBJECTIVE-We evaluated mononuclear cell (MNC) preactivation in women with Polycystic Ovary Syndrome (PCOS) by examining the effect of in vitro lipopolysaccharide (LPS) exposure on cytokine release in the fasting state.

STUDY DESIGN-Twenty women with PCOS (10 lean, 10 obese) and 20 weight-matched controls (10 lean, 10 obese) volunteered for study participation. Tumor necrosis factor-a (TNF a) and interleukin-6 (IL-6) release was measured from mononuclear cell isolated from fasting blood samples and cultured in the presence and absence of lipopolysaccharide. Plasma IL-6 was measured from the same fasting blood samples. Insulin sensitivity was derived from an oral glucose tolerance test using the Matsuda index and truncal fat was measured by dual energy $\mathrm{x}$-ray absorptiometry.

RESULTS-The percent change from baseline in TNFa and IL-6 release from mononuclear cell following lipopolysaccharide exposure was increased (pitalic $>0.04$ ) in lean and obese women with

C 2014 Mosby, Inc. All rights reserved.

CORRESPONDING AUTHOR: Frank González, Indiana University School of Medicine, Department of Obstetrics and Gynecology, AOC Room 6046, 550 N. University Boulevard, Indianapolis, IN 46202, gonzalef@iupui.edu, TELEPHONE \#: (317) 944-4058, FAX \#: (317) 944-7417.

LOCATIONS OF STUDY CONDUCT: Cleveland Ohio and Indianapolis, Indiana

DISCLOSURE STATEMENT: The authors report no conflict of interest.

PAPER PRESENTATION: This work was presented at the $7^{\text {th }}$ Annual Meeting of Androgen Excess and PCOS Society, Washington, D.C., June 9, 2009.

Publisher's Disclaimer: This is a PDF file of an unedited manuscript that has been accepted for publication. As a service to our customers we are providing this early version of the manuscript. The manuscript will undergo copyediting, typesetting, and review of the resulting proof before it is published in its final citable form. Please note that during the production process errors may be discovered which could affect the content, and all legal disclaimers that apply to the journal pertain. 
PCOS and obese controls compared with lean controls. Plasma IL-6 was increased (pbold $>0.02$ ) in obese women with PCOS compared with lean women with PCOS, which in turn was increased $(p<0.02)$ compared with lean controls. The mononuclear cell -derived TNFa and IL-6 responses from mononuclear cell were negatively correlated with insulin sensitivity $(\mathrm{p}<0.03)$ and positively correlated with testosterone $(\mathrm{p}<0.03)$ and androstenedione $(\mathrm{p}<0.006)$ for the combined groups. Plasma IL-6 was positively correlated with percent truncal fat $(\mathrm{p}<0.008)$.

CONCLUSIONS-In PCOS, increased cytokine release from mononuclear cell following lipopolysaccharide exposure in the fasting state reveals the presence of mononuclear cell preactivation. Importantly, this phenomenon is independent of obesity and may contribute to the development of insulin resistance and hyperandrogenism in PCOS. In contrast, the source of plasma IL-6 elevations in PCOS may be excess adiposity.

\section{Keywords}

inflammation; lipopolysaccharide; mononuclear cell preactivation

\section{Introduction}

The Polycystic Ovary Syndrome (PCOS) affects as many as 15\% of reproductive-age women and is characterized by hyperandrogenism, chronic oligo- or anovulation and polycystic ovaries. ${ }^{1,2}$ Obesity and insulin resistance are often present in PCOS and the compensatory hyperinsulinemia is thought to promote the hyperandrogenism. ${ }^{3,4}$ Many young women with PCOS also possess risk factors for cardiovascular disease such as metabolic syndrome, type 2 diabetes, dyslipidemia and hypertension which are associated with atherosclerosis. ${ }^{5,6}$ In PCOS, oxidative stress and chronic low-grade inflammation have been implicated in the development of insulin resistance and accelerated atherogenesis. ${ }^{7-9}$ Women with PCOS exhibit increased circulating levels of protein carbonyls, tumor necrosis factor-a (TNF a) and interleukin-6 (IL-6), decreased insulin signaling and a higher prevalence of coronary artery calcification. ${ }^{10-14}$

Our previous studies have highlighted the ability of nutrient ingestion to trigger a prooxidant proinflammatory response from peripheral blood mononuclear cells (MNC) that is independent of obesity. ${ }^{8,15-19}$ Indeed, MNC of lean women with PCOS exhibit increases in reactive oxygen species (ROS) generation and nuclear factor $\kappa \mathrm{B}(\mathrm{NF} \kappa \mathrm{B})$ activation following ingestion of glucose and lipid. ${ }^{17,20} \mathrm{NF \kappa B}$ regulates the transcription of a variety of inflammatory mediators including that of TNFa and IL-6. These cytokines exert positive feedback to up-regulate the preceding molecular events that mediate insulin resistance and atherogenesis. ${ }^{21,22}$ Thus, MNC of women with PCOS have an increased sensitivity to nutrient ingestion.

MNC preactivation in the fasting state may account for increased MNC sensitivity in PCOS. In this instance, the NFkB inflammation pathway that culminates in cytokine release from MNC may already be upregulated prior to nutrient ingestion similar to what has been reported in obesity. ${ }^{23}$ As such, we evaluated MNC obtained in the fasting state for the amount of TNFa and IL-6 release following in vitro exposure to lipopolysaccharide (LPS) and also evaluated the status of fasting plasma IL-6 in women with PCOS. We anticipated 
that plasma IL- 6 would be elevated in these women based on previous studies. ${ }^{14}$ However, we hypothesized that MNC-derived cytokine release is increased in response to in vitro LPS exposure in women with PCOS compared with weight-matched controls; and that this cytokine response to LPS along with plasma IL-6 levels are related to abdominal adiposity, insulin sensitivity and circulating androgens.

\section{Materials and Methods}

\section{Subjects}

Twenty women with PCOS (10 lean and 10 obese) 20-34 years of age and 20 weightmatched control subjects (10 lean and 10 obese) 20-39 years of age volunteered for study participation. Some subjects in the current study were involved in our previous work on PCOS and insulin resistance. ${ }^{16}$ Additional subjects were recruited via newspaper advertisements and flyers within the Indiana University community between the years 2011 and 2013. Obesity was defined as a body mass index (BMI) between 30 and $40 \mathrm{~kg} / \mathrm{m}^{2}$. Lean subjects had a BMI between 18 and $25 \mathrm{~kg} / \mathrm{m}^{2}$. The women with PCOS were diagnosed on the basis of oligo-amenorrhea and hyperandrogenemia after excluding nonclassic congenital adrenal hyperplasia, Cushing's Syndrome, hyperprolactinemia and thyroid disease. Polycystic ovaries were present on ultrasound in all subjects with PCOS. All control subjects had regular menses lasting 25 to 35 days and a luteal range serum progesterone level consistent with ovulation ( $>5 \mathrm{ng} / \mathrm{ml})$. All control subjects exhibited normal circulating androgen levels and did not have any skin manifestations of androgen excess or polycystic ovaries on ultrasound.

Diabetes and inflammatory illnesses were excluded in all subjects. None of them suffered from depression, smoked tobacco, ingested more than two alcoholic beverages per month or used medications that could impact carbohydrate metabolism or immune function for a minimum of 6 weeks before beginning the study. All subjects were sedentary defined as exercise less than once a month during the 6 months before study participation. Written informed consent was obtained from all subjects according to Institutional Review Board guidelines.

\section{Study Design}

All study subjects were provided with a healthy diet consisting of 50\% carbohydrate, $35 \%$ fat and $15 \%$ protein for 3 consecutive days before testing between days 5 and 8 after the onset of menstruation. All but one of the subjects was compliant with the diet based on completion of a checklist of consumed food and inspection of returned empty food containers. The less compliant individual was a lean control who consumed $85 \%$ of the food provided. Testing began with an assessment of body composition. After an overnight fast of $\sim 12$ hours, a blood sample was obtained for MNC isolation and culture, and to isolate plasma that was stored at $-80^{\circ} \mathrm{C}$ until assayed for IL-6. All study subjects then underwent an oral glucose tolerance test (OGTT) to assess insulin sensitivity. 


\section{Body Composition Assessment}

Height without shoes was measured to the nearest $1.0 \mathrm{~cm}$. Body weight was measured to the nearest $0.1 \mathrm{~kg}$. Waist circumference was measured at the level of the umbilicus and used to estimate abdominal adiposity. In addition, all subjects underwent dual energy x-ray absorptiometry to determine percent total body fat and percent truncal fat using the QDR 4500 Elite model scanner (Hologic Inc., Waltham, MA) as previously described. ${ }^{15,24}$

\section{MNC Culture}

MNC were isolated by density gradient centrifugation in Histopaque-1077 (Sigma-Aldrich Co., St. Louis, MO). The cells were washed twice in pyrogen-free saline, resuspended in RPMI $\left(0.3 \mathrm{mg} / \mathrm{ml}\right.$ L-glutamine, $100 \mathrm{U} / \mathrm{ml}$ penicillin, $100 \mathrm{ug} / \mathrm{ml}$ streptomycin) with $\mathrm{TCH}^{\mathrm{TM}}$ Serum Replacement (MD Biomedicals, Inc., Irvine, CA) and seeded in coated culture plates (VWR International, West Chester, PA) at a concentration of $2.5 \times 10^{6} \mathrm{cells} / \mathrm{ml}$. The cells were then incubated ( $95 \%$ humidity, $5 \% \mathrm{CO}_{2}, 37^{\circ} \mathrm{C}$ ) for 24 hours in the presence (exposed) and absence (unexposed) of $1 \mathrm{ng} / \mathrm{ml}$ of LPS endotoxin from Escherichia coli 0127:B8 (Sigma-Aldrich Co. LLC, St. Louis, MO). Culture supernatants were collected and stored at $-80^{\circ} \mathrm{C}$ until assayed for TNFa and IL-6.

\section{Oral Glucose Tolerance Test}

Blood samples were drawn at $0,30,60,90,120$ and 180 minutes after ingestion of a $75 \mathrm{gm}$ glucose beverage to measure glucose and insulin. Plasma glucose concentrations were assayed immediately, and insulin measurements were performed later from plasma stored at $-80^{\circ} \mathrm{C}$. Insulin sensitivity was derived using the Matsuda index formula (IS OGTT $_{\text {) }}$ 10,000 divided by the square root of (fasting glucose $\mathrm{x}$ fasting insulin) $\mathrm{x}$ (mean glucose $\mathrm{x}$ mean insulin). ${ }^{25}$ This particular formula is highly correlated with insulin sensitivity measurements using the gold standard hyperinsulinemic-euglycemic clamp procedure. ${ }^{25-27}$

\section{Serum, Plasma and Culture Supernatant Measurements}

Serum luteinizing hormone ( $\mathrm{LH})$, testosterone, androstenedione and dehydroepiandrosterone-sulfate (DHEA-S) levels were measured by RIA (Siemens Medical Solutions Diagnostics, Los Angeles, CA). Plasma glucose was measured by the glucose oxidase method (YSI 2300 STAT Plus, Yellow Springs, OH), while plasma insulin was measured by a double antibody RIA (Millipore, St. Charles, MO). Plasma IL-6 concentrations along with those of TNFa and IL-6 in MNC culture supernatants were measured by ELISA (eBioscience, San Diego, CA). The interassay and intraassay coefficients of variation for all assays did not exceed $7.4 \%$ and $12 \%$, respectively.

\section{Statistics}

Data were analyzed using StatView (SAS Institute, Cary, NC). All values were initially examined graphically for departure from normality, and the natural logarithm transformation was applied as needed. Descriptive data and change from baseline of variables were compared between groups using ANOVA for multiple group comparisons. The source of significance by ANOVA was identified by Tukey's post hoc test. Furthermore, ANCOVA was performed to confirm significance of inflammation variables using significantly altered 
metabolic parameters as covariates that might influence inflammation when comparing lean PCOS vs. lean controls or obese PCOS vs. obese controls. The treatment effect was determined by calculating the percent change in LPS-exposed cytokine release from the unexposed baseline for each subject in view of intersubject variability. Pearson linear regression was employed for correlation analyses using the method of least squares. Data are presented as mean $\pm \mathrm{SE}$, and results with a two-tailed a-level of 0.05 were considered significant.

\section{Results}

\section{Age, Body Composition, Blood Pressure and Lipids}

All four groups were similar in age and height (Table 1). Obese subjects had significantly $(\mathrm{p}<0.05)$ higher weight, body mass index (BMI), percent total body fat, percent truncal fat and waist circumference compared with lean subjects whether or not they had PCOS. However, these measures of body composition were similar when women with PCOS were compared with weight-matched controls.

Systolic blood pressure was similar among groups. Diastolic blood pressure was significantly $(\mathrm{p}<0.05)$ higher in obese controls compared with lean women with PCOS and lean controls, but mean values were in the normotensive range. The levels of total cholesterol, triglyceride and high and low density lipoprotein cholesterol were similar among groups.

\section{Plasma Hormone Levels, Glycemic Status and Insulin Sensitivity}

Women with PCOS exhibited significantly $(\mathrm{p}<0.05)$ higher serum levels of LH, testosterone, androstenedione and DHEA-S compared with control subjects regardless of weight class (Table 1). Women with PCOS who were lean had significantly $(\mathrm{p}<0.05)$ higher serum LH levels compared with those who were obese.

Women with PCOS and controls exhibited similar glucose levels while fasting and 2 hours post glucose ingestion regardless of weight status. All subjects had a normal glucose response during the OGTT, with fasting glucose levels $<100 \mathrm{mg} / \mathrm{dl}$ and 2-hour glucose levels ranging between 75 and $137 \mathrm{mg} / \mathrm{dl}$. Fasting insulin levels were significantly higher $(\mathrm{p}<0.05)$ in obese women with PCOS compared with lean women with PCOS and both control groups and in obese controls compared with lean controls. The IS $_{\text {OGTT }}$ was significantly higher $(\mathrm{p}<0.05)$ in obese subjects regardless of PCOS status compared with lean controls and in lean women with PCOS compared with lean controls.

\section{MNC-Derived TNFa and IL-6 Release and Plasma IL-6}

Baseline TNFa and IL-6 release from MNC in the fasting state was similar in all four groups (data not shown). The change from baseline in TNFa and IL-6 release from MNC following LPS exposure was significantly $(\mathrm{p}<0.04)$ greater in in both PCOS groups and obese controls compared with lean controls (Figure 1A-B).

Fasting plasma IL-6 was significantly $(\mathrm{p}<0.02)$ higher in obese subjects whether or not they had PCOS and lean women with PCOS compared with lean controls (Figure 2). Obese 
women with PCOS also exhibited significantly $(\mathrm{p}<0.02)$ higher fasting plasma IL-6 levels compared with lean women with PCOS.

The MNC-derived TNFa and IL-6 responses and fasting plasma IL-6 remained significantly increased in lean women with PCOS when comparing the lean groups after controlling for insulin sensitivity ( $\mathrm{IS}_{\mathrm{OGTT}}$ ), and remained similar when comparing the obese groups after controlling for fasting insulin.

\section{Correlations}

Waist circumference was positively correlated with BMI $(r=0.76, p<0.0001)$, percent body fat $(r=0.61, p<0.0001)$ and percent truncal fat $(r=0.68, p<0.0001)$ and IS $_{\text {OGTT }}$ was negatively correlated with BMI $(r=-0.49, p<0.002)$, waist circumference $(r=-0.45$, $\mathrm{p}<0.005)$ and percent truncal fat $(\mathrm{r}=-0.42, \mathrm{p}<0.008)$ for the combined groups.

The change from baseline in IL-6 release from MNC following LPS exposure was positively correlated with that of TNFa and plasma IL-6 for the combined groups (Table 2). Fasting plasma IL-6 was positively correlated with BMI, waist circumference, percent body fat and percent truncal fat. The MNC-derived TNFa and IL-6 responses and plasma IL-6 were negatively correlated with IS $_{\text {OGTT }}$ and were positively correlated with serum levels of testosterone and androstenedione. There was also a positive correlation between MNCderived TNFa response and serum $\mathrm{LH}(\mathrm{r}=0.50, \mathrm{p}<0.002)$.

In women with PCOS, fasting plasma IL-6 was positively correlated with the MNC-derived IL-6 response $(r=0.63, p<0.005)$, percent body fat $(r=0.53, p<0.002)$, percent truncal fat $(r=$ $0.60, \mathrm{p}<0.008)$ and serum levels of testosterone $(\mathrm{r}=0.46, \mathrm{p}<0.05)$ and DHEA-S $(\mathrm{r}=0.49$, $\mathrm{p}<0.04)$. There was also a positive correlation between the MNC-derived IL-6 response and serum testosterone $(r=0.56, \mathrm{p}<0.02)$.

\section{Comment}

Our data provide the first clear evidence that in PCOS, MNC are preactivated in the fasting state and that this phenomenon is independent of obesity. Moreover, a proinflammatory stimulus in the form of LPS increases MNC-derived cytokine release in the fasting state in lean women with PCOS compared with lean controls. There are also independent associations of cytokine release from MNC following LPS exposure with insulin sensitivity, LH, and androgens. Furthermore circulating IL-6 levels are directly associated with measures of adiposity. Thus, MNC preactivation may contribute to the development of insulin resistance and hyperandrogenism while excess abdominal adiposity may be a source of plasma IL-6 elevations in PCOS.

The MNC of lean healthy reproductive-age women do not appear to be preactivated. There is minimal increase in TNFa and IL-6 release from resting MNC following in vitro LPS exposure in lean controls. This is consistent with our previous reports of the MNC-derived responses of these cytokines in the fasting state following in vitro glucose exposure in lean healthy young women. ${ }^{16,28}$ These observations are important because the collective effects of TNFa and IL-6 are responsible for mediating insulin resistance and atherogenesis. ${ }^{21,22}$ 
Thus, the limited MNC-derived response to proinflammatory stimuli in lean young women may serve to maintain insulin sensitivity and curtail atherogenesis to optimize glucose disposal and preserve blood vessel integrity.

In contrast, resting MNC of women with PCOS are in a proinflammatory state. TNFa and IL-6 release from MNC is increased in response to in vitro LPS exposure in lean women with PCOS compared with lean controls. Obese individuals regardless of PCOS status also exhibit increases in these parameters compared with lean controls. These results mimic our previous findings for these cytokines in response to in vitro glucose exposure particularly in obese women with PCOS. ${ }^{16,28}$ These proinflammatory responses provide evidence of MNC preactivation as the underpinning for the increased MNC sensitivity to nutrient ingestion observed in vivo in women with PCOS. 8,9,17,29 The inverse relationship between LPSstimulated cytokine release and insulin sensitivity supports the concept that MNC preactivation may ultimately play a part in the mechanism of insulin resistance. In the case of obese individuals regardless of PCOS status, the impetus for MNC preactivation may be cytokines such as TNFa and IL-6 that are secreted into the circulation from the expanded adipose tissue compartment as a result of inflammation induced by hypoxia-related cell death. ${ }^{23,30}$ In fact, there is a positive association between fasting plasma IL- 6 and the MNCderived IL-6 response. Almost one-third of lean women with PCOS exhibit excess abdominal adiposity and this may contribute to MNC preactivation. ${ }^{31}$ However, excess adiposity does not completely account for our findings in this group based on our recent report of increased MNC sensitivity to glucose ingestion in lean women with PCOS who lack excess abdominal adiposity. ${ }^{27,32}$ Furthermore, we have recently shown that induction of hyperandrogenemia in lean healthy reproductive-age women without PCOS who lack inflammation can activate and sensitize MNC to glucose, but that suppression of hyperandrogenemia in lean women with PCOS does not reduce the inflammatory load. ${ }^{33,34}$ Thus, it is possible that hyperandrogenism is the progenitor of nutrient-induced inflammation in PCOS, but is not required for maintenance of this phenomenon in the chronic state.

Our data suggest that in PCOS, the chronic presence of excess adiposity may be a primary source of elevated cytokines such as IL-6 in the circulation. Fasting plasma IL-6 levels are highest in obese women with PCOS compared with lean women with PCOS who in turn have IL-6 levels that are higher compared with lean controls. This pattern mimics the one observed for insulin sensitivity in our study subjects. Furthermore, measures of adiposity, including abdominal fat are positively associated with fasting plasma IL-6 levels. Roughly half of the IL- 6 in the expanded adipose mass of obese individuals is produced by MNCderived macrophages and serves as a paracrine stimulator of adipocyte IL- 6 production. ${ }^{35}$ Insulin sensitivity is also inversely related to fasting plasma IL-6 and abdominal adiposity. Thus, circulating MNC and excess adipose tissue may be joint contributors to systemic inflammation and insulin resistance in PCOS.

In PCOS, MNC preactivation may ultimately result in hyperandrogenism. Circulating $\mathrm{LH}$, testosterone, androstenedione and DHEA-S are all directly related to MNC-derived cytokine release and/or fasting plasma IL-6 levels. This is supported by our findings in previous studies. ${ }^{8,9,16,17,29,32}$ While the relationship with LH raises the possibility that inflammation 
contributes to pituitary LH hypersecretion in PCOS to enhance androgen production, impact at the local level is well characterized. MNC-derived macrophages are present in the ovary. ${ }^{36}$ Exposure of cultured theca cells to prooxidants increases the mRNA content of CYP17, the androgen producing steroidogenic enzyme, whereas exposure to anti-oxidants such as resveratrol and statins decreases CYP17 mRNA content. ${ }^{37,38}$ Statins are also capable of inhibiting proliferation of theca cells from rat and human polycystic ovaries in vitro. ${ }^{39,40}$ Thus, excess ovarian androgen production in PCOS may be the consequence of an oxidative stress-induced local inflammatory response from preactivated $\mathrm{MNC}$ that migrate into the polycystic ovary. Interestingly, PCOS theca cells in long-term culture produce excess androgens in the absence of macrophages. ${ }^{41}$ Although this latter finding may represent a fostering effect of chronic in vitro conditions, it raises the possibility that a proinflammatory milieu within the polycystic ovary confers a permanent independent propensity for PCOS theca cell hyperandrogenism.

In conclusion, cytokine release from MNC following LPS exposure in the fasting state is increased in women with PCOS. This phenomenon is consistent with preactivation of circulating MNC and is independent of obesity. MNC preactivation in PCOS may be the cause of increased MNC sensitivity to proinflammatory nutrients that may ultimately contribute to insulin resistance and hyperandrogenism. Furthermore, excess abdominal adiposity may be the source of plasma IL-6 elevations in this disorder.

\section{Acknowledgments}

FUNDING: This research was supported by grant HD-048535 to F.G. from the National Institutes of Health.

\section{References}

1. Fauser BC, Tarlatzis BC, Rebar RW, et al. Consensus on women's health aspects of polycystic ovary syndrome (PCOS): the Amsterdam ESHRE/ASRM-Sponsored 3rd PCOS Consensus Workshop Group. Fertil Steril. 2012; 97:28-38.e25. [PubMed: 22153789]

2. The Rotterdam ESHRE/ASRM-Sponsored PCOS Conference Workshop Group. Revised 2003 consensus on diagnostic criteria and long-term health risks related to polycystic ovary syndrome. Fertil Steril. 2004; 81:19-25.

3. Burghen GA, Givens JR, Kitabachi AE. Correlation of hyperandrogenism with hyperinsulinemia in polycystic ovarian disease. J Clin Endocrinol Metab. 1980; 50:113-6. [PubMed: 7350174]

4. Dunaif A, Segal KR, Futterweit W, Dobrjansky A. Profound insulin resistance, independent of obesity in polycystic ovary syndrome. Diabetes. 1989; 38:1165-74. [PubMed: 2670645]

5. Wild RA, Carmina E, Diamanti-Kandarakis E, et al. Assessment of cardiovascular risk and prevention of cardiovascular disease in women with the polycystic ovary syndrome: a consensus statement by the Androgen Excess and Polycystic Ovary Syndrome (AE-PCOS) Society. J Clin Endocrinol Metab. 2010; 95:2038-49. [PubMed: 20375205]

6. Freeman MS, Mansfield MW, Barrett JH, Grant PJ. Insulin resistance: an atherothrombotic syndrome. Thromb Haemost. 2003; 89:161-8. [PubMed: 12540966]

7. Kelly CC, Lyall H, Petrie JR, Gould GW, Connell JMC, Sattar N. Low grade chronic inflammation in women in women with polycystic ovary syndrome. J Clin Endocrinol Metab. 2001; 86:2453-5. [PubMed: 11397838]

8. González F, Rote NS, Minium J, Kirwan JP. Increased activation of nuclear factor $\kappa \mathrm{B}$ triggers inflammation and insulin resistance in polycystic ovary syndrome. J Clin Endocrinol Metab. 2006; 91:150-12. 
9. González F, Rote NS, Minium J, Kirwan JP. Glucose ingestion stimulates atherothrombotic inflammation in polycystic ovary syndrome. Am J Physiol Endocrinol Metab. 2013; 304:E375-83. [PubMed: 23249695]

10. González F, Thusu K, Abdel-Rahman E, Prabhala A, Tomani M, Dandona P. Elevated serum levels of tumor necrosis factor $\mathrm{a}$ in normal-weight women with polycystic ovary syndrome. Metabolism. 1999; 48:437-41. [PubMed: 10206434]

11. Fenkci V, Fenkci S, Yilmazer M, Serteser M. Decreased total antioxidant status and increased oxidative stress in women with polycystic ovary syndrome may contribute to the risk of cardiovascular disease. Fertil Steril. 2003; 80:123-7. [PubMed: 12849813]

12. Talbott EO, Zborowski JV, Rager JR, Boudreaux MY, Edmundowicz DA, Guzick DS. Evidence for an association between metabolic cardiovascular syndrome and coronary and aortic calcification among women with polycystic ovary syndrome. J Clin Endocrinol Metab. 2004; 89:5454-61. [PubMed: 15531497]

13. Corbould A, Kim YB, Youngren JF, et al. Insulin resistance in the skeletal muscle of women with PCOS involves intrinsic and acquired defects in insulin signaling. Am J Physiol Endocrinol Metab. 2005; 288:E1047-54. [PubMed: 15613682]

14. Tarkun I, Cetinarslan B, Türemen E, Cantürk Z, Biyikli M. Association between circulating tumor necrosis factor-alpha, interleukin-6, and insulin resistance in normal-weight women with polycystic ovary syndrome. Metab Syndr Relat Disord. 2006; 4:122-8. [PubMed: 18370758]

15. González F, Rote NS, Minium J, Kirwan JP. Hyperglycemia alters tumor necrosis factor-a release from mononuclear cells in women with polycystic ovary syndrome. J Clin Endocrinol Metab. 2005; 90:5336-42. [PubMed: 15985479]

16. González F, Rote NS, Minium J, Kirwan JP. In vitro evidence that hyperglycemia stimulates tumor necrosis factor-a release in obese women with polycystic ovary syndrome. J Endocrinol. 2006; 88:521-9. [PubMed: 16522732]

17. González F, Rote NS, Minium J, Kirwan JP. Reactive oxygen species-induced oxidative stress in the development of insulin resistance and hyperandrogenism in polycystic ovary syndrome. J Clin Endocrinol Metab. 2006; 91:336-40. [PubMed: 16249279]

18. González F, Rote NS, Minium J, Kirwan JP. Evidence of proatherogenic inflammation in polycystic ovary syndrome. Metabolism. 2009; 58:954-62. [PubMed: 19375763]

19. González F, Rote NS, Minium J, Kirwan JP. Elevated circulating levels of macrophage migration inhibitory factor in polycystic ovary syndrome. Cytokine. 2010; 51:240-4. [PubMed: 20598902]

20. Abdelhadi OA, Shepard MK, Sia CL, Garrett TJ, González F. Activation of nuclear factor $\kappa \mathrm{B}$ in response to cream ingestion is related to ovarian androgen hypersecretion in polycystic ovary syndrome. Fertil Steril. 2013; 100(2 Suppl):S39.

21. Barnes PJ, Karin M. Nuclear factor $-\kappa B$ : a pivotal transcription factor in chronic inflammatory diseases. N Engl J Med. 1997; 336:1066-71. [PubMed: 9091804]

22. Rui L, Aguirre V, Kim JK, et al. Insulin/IGF-1 and TNF-a stimulate phosphorylation of IRS-1 at inhibitory Ser $^{307}$ via distinct pathways. J Clin Invest. 2001; 107:181-9. [PubMed: 11160134]

23. Ghanim H, Aljada A, Hofmeyer D, Syed T, Dandona P. Circulating mononuclear cells in the obese are in a proinflammatory state. Circulation. 2004; 110:1564-1571. [PubMed: 15364812]

24. Taylor RW, Keil D, Gold EJ, Williams SM, Goulding A. Body mass index, waist girth, and waist to hip ratio as indexes of total and regional adiposity in women: evaluation using receiver operating characteristic curves. Am J Clin Nutr. 1998; 67:44-9. [PubMed: 9440374]

25. Matsuda M, DeFronzo R. Insulin sensitivity indices obtained from oral glucose tolerance testing. Diabetes Care. 1999; 22:1462-70. [PubMed: 10480510]

26. Kirwan JP, Huston-Presley L, Kalhan SC, Catalano PM. Clinically useful estimates of insulin sensitivity during pregnancy: validation studies in women with normal glucose tolerance and gestational diabetes mellitus. Diabetes Care. 2001; 24:1602-7. [PubMed: 11522706]

27. Ciampelli M, Leoni F, Cucinelli F, Mancuso S, Panunzi S, De Gaetano A, et al. Assessment of insulin sensitivity from measurements in the fasting state and during an oral glucose tolerance test in polycystic ovary syndrome and menopausal patients. J Clin Endocrinol Metab. 2005; 90:13981406. [PubMed: 15598698] 
28. González F, Rote NS, Minium J, Kirwan JP. In vitro evidence that hyperglycemia stimulates increased IL-6 release from mononuclear cells of obese women with polycystic ovary syndrome. Fertil Steril. 2006; 86(2 Suppl):S449-50.

29. González F, Sia CL, Shepard MK, Rote NS, Minium J. Inflammation in response to glucose ingestion is independent of excess abdominal adiposity in normal weight women with polycystic ovary syndrome. J Clin Endocrinol Metab. 2012; 97:4071-9. [PubMed: 22904174]

30. Cinti S, Mitchell G, Barbatelli G, Murano I, Ceresi E, Faloia E, et al. Adipocyte death defines macrophage localization and function in adipose tissue of obese mice and humans. J Lipid Res. 2005; 46:2347-55. [PubMed: 16150820]

31. Carmina E, Bucchierri S, Esposito A, et al. Abdominal fat quantity and distribution in women with polycystic ovary syndrome and extent of its relation to insulin resistance. J Clin Endocrinol Metab. 2007; 92:2500-5. [PubMed: 17405838]

32. González F, Sia CL, Shepard MK, Rote NS, Minium J. Hyperglycemia-induced oxidative stress is independent of excess abdominal adiposity in normal weight women with polycystic ovary syndrome. Hum Reprod. 2012; 27:3560-8. [PubMed: 22940766]

33. González F, Nair KS, Daniels JK, Basal E, Schimke JM. Hyperandrogenism sensitizes mononuclear cells to promote glucose-induced inflammation in lean reproductive-age women. Am J Physiol Endocrinol Metab. 2012; 302:E297-306. [PubMed: 22045316]

34. González F, Sia CL, Stanczyk FZ, Blair HE, Krupa ME. Hyperandrogenism exerts an antiinflammatory effect in obese women with polycystic ovary syndrome. Endocrine. 2012; 42:72635. [PubMed: 22752961]

35. Weisberg SP, McCann D, Desai M, Rosenbaum M, Leibel RL, Ferrante AW Jr. Obesity is associated with macrophage accumulation in adipose tissue. J Clin Invest. 2003; 112:1796-1808. [PubMed: 14679176]

36. Best CL, Pudney J, Welch WR, Burger N, Hill JA. Localization and characterization of white blood cell populations within the human ovary throughout the menstrual cycle and menopause. Hum Reprod. 1996; 11:790-7. [PubMed: 8671330]

37. Piotrowski PC, Rzepczynska IJ, Kwintkiewicz J, Duleba AJ. Oxidative stress induces expression of CYP11A, CYP17, STAR and 3-HSD in rat theca-interstitial cells. J Soc Gynecol Invest. 2005; 12(2 Suppl):319A.

38. Wong DH, Villanueva JA, Cress AB, Sokalska A, Ortega I, Duleba AJ. Resveratrol inhibits the mevalonate pathway and potentiates the antiproliferative effects of simvastatin in rat thecainterstitial cells. Fertil Steril. 2011; 96:1252-8. [PubMed: 21907337]

39. Spazynsky RZ, Arici A, Duleba AJ. Tumor necrosis factor alpha stimulates proliferation of rat ovarian theca-interstitial cells. Biol Reprod. 1999; 61:993-8. [PubMed: 10491635]

40. Sokalska A, Piotrowski PC, Rzepczynska IJ, Cress A, Duleba AJ. Statins inhibit growth of human theca-interstitial cells in PCOS and non-PCOS tissues independently of cholesterol availability. J Clin Endocrinol Metab. 2012; 95:5390-4. [PubMed: 20826585]

41. Nelson VL, Legro RS, Strauss JF 3rd, McAllister JM. Augmented androgen production is a stable steroidogenic phenotype of propagated theca cells from polycystic ovaries. Mol Endocrinol. 1999; 13:946-57. [PubMed: 10379893] 

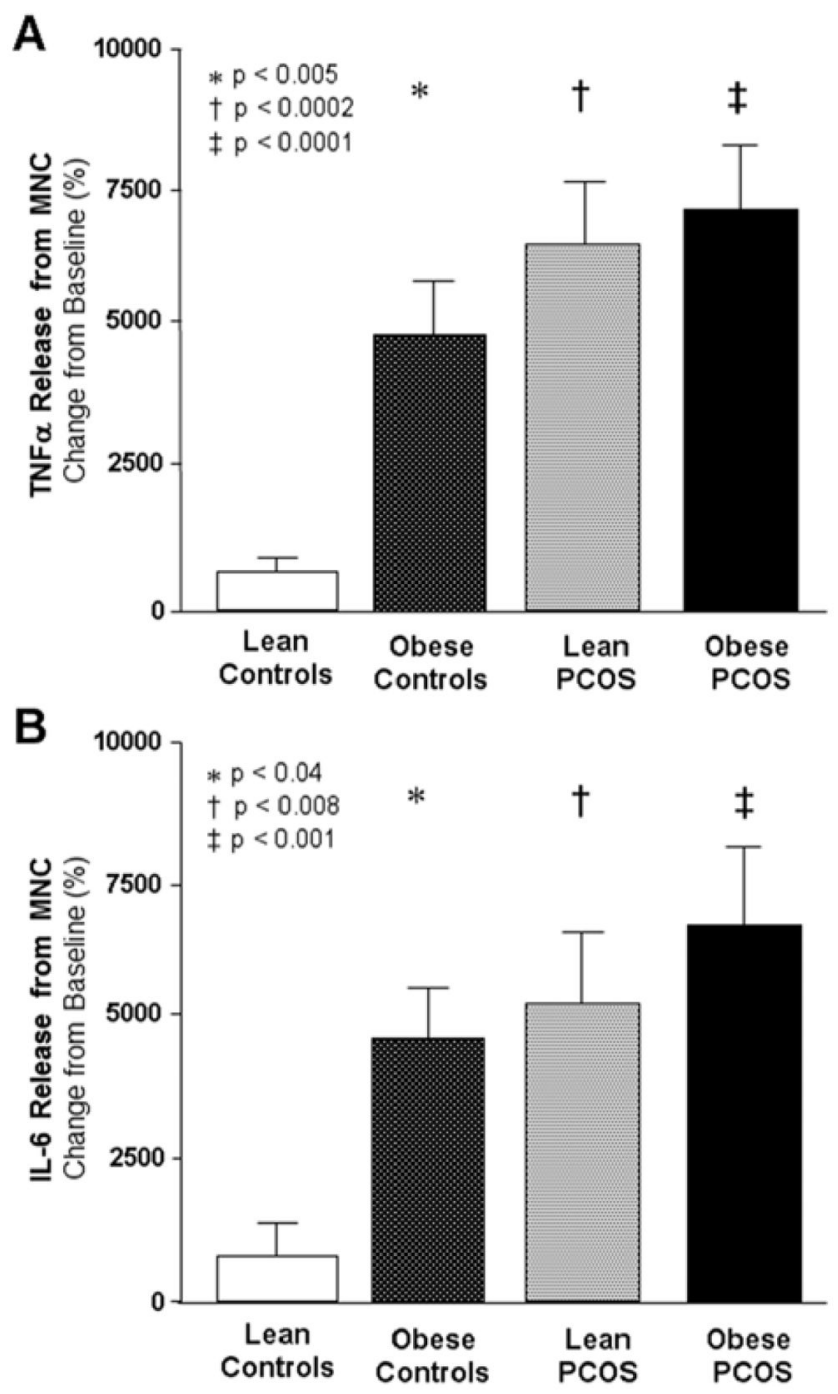

FIGURE 1. Mononuclear cell cytokine release

Change from baseline (\%, percent) in lipopolysaccharide (LPS)-exposed (A) tumor necrosis factor-a (TNFa) and (B) interleukin-6 (IL-6) release from an unexposed baseline in mononuclear cells isolated from fasting samples and cultured for 24 hours. * Significantly higher in obese controls compared with lean controls for TNFa $(\mathrm{P}<0.005)$ and IL-6 $(\mathrm{P}<0.04)$. $\dagger$ Significantly higher in lean women with PCOS compared with lean controls for TNFa $(\mathrm{P}<0.0002)$ and IL-6 $(\mathrm{P}<0.008)$. $\$$ Significantly higher in obese women with PCOS compared with lean controls for TNFa $(\mathrm{P}<0.0001)$ and IL-6 $(\mathrm{P}<0.001)$. 


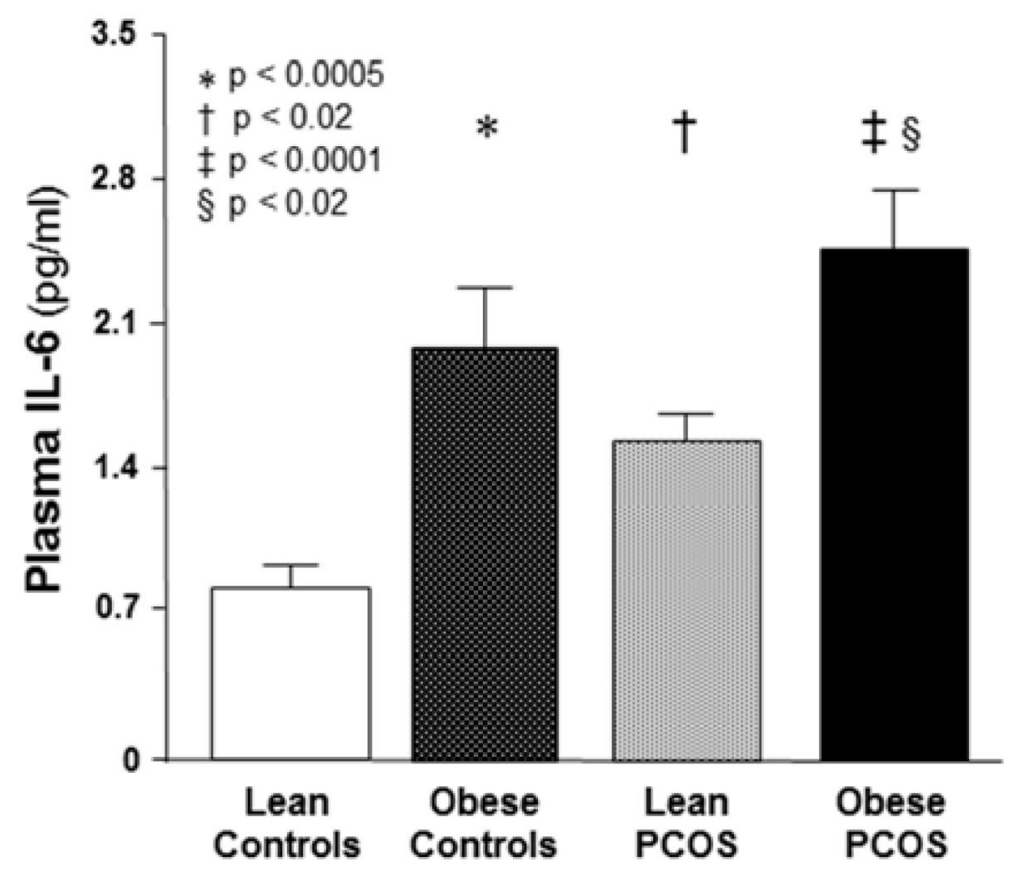

FIGURE 2. Fasting plasma interleukin-6 levels

* Significantly higher in obese controls compared with lean controls $(\mathrm{P}<0.0005) . \dagger$ Significantly higher in lean women with PCOS compared with lean controls $(\mathrm{P}<0.02)$. Significantly higher in obese women with PCOS compared with lean controls $(\mathrm{P}<0.0001) . \S$ Significantly higher in obese women with PCOS compared with lean women with PCOS $(\mathrm{P}<0.02)$. 
TABLE 1

Age, body composition, endocrine and metabolic parameters of subjects

\begin{tabular}{|c|c|c|c|c|}
\hline & \multicolumn{2}{|c|}{ CONTROLS } & \multicolumn{2}{|c|}{ PCOS } \\
\hline & Lean & Obese & Lean & Obese \\
\hline Age, yr & $30 \pm 2$ & $30 \pm 2$ & $27 \pm 2$ & $26 \pm 2$ \\
\hline Height, cm & $165.9 \pm 1.3$ & $164.0 \pm 2.1$ & $162.4 \pm 3.4$ & $165.5 \pm 1.7$ \\
\hline Body weight, $\mathrm{kg}$ & $62.8 \pm 2.0$ & $93.4 \pm 3.4^{a, b}$ & $61.1 \pm 1.9$ & $96.6 \pm 3.5^{c, d}$ \\
\hline Body mass index, $\mathrm{kg} / \mathrm{m}^{2}$ & $22.8 \pm 0.5$ & $34.7 \pm 0.9^{a, b}$ & $23.3 \pm 0.7$ & $35.2 \pm 1.0^{c, d}$ \\
\hline Total body fat, $\%$ & $32.9 \pm 1.7$ & $42.3 \pm 0.8^{a, b}$ & $30.3 \pm 1.4$ & $44.5 \pm 1.2^{c, d}$ \\
\hline Truncal fat, \% & $30.2 \pm 1.7$ & $41.7 \pm 0.8^{a, b}$ & $29.3 \pm 2.2$ & $46.1 \pm 1.1^{c, d}$ \\
\hline Waist circumference, $\mathrm{cm}$ & $74.2 \pm 1.4$ & $100.8 \pm 2.9^{a, b}$ & $77.1 \pm 2.3$ & $99.3 \pm 5.1^{c, d}$ \\
\hline Systolic blood pressure, $\mathrm{mmHg}$ & $109 \pm 2$ & $118 \pm 4$ & $112 \pm 2$ & $118 \pm 4$ \\
\hline Diastolic blood pressure, $\mathrm{mmHg}$ & $64 \pm 1$ & $75 \pm 3^{a, b}$ & $65 \pm 3$ & $72 \pm 4$ \\
\hline Total cholesterol, mg/dl & $177 \pm 12$ & $188 \pm 20$ & $177 \pm 12$ & $178 \pm 12$ \\
\hline Triglycerides, mg/dl & $63 \pm 18$ & $113 \pm 35$ & $122 \pm 34$ & $94 \pm 14$ \\
\hline $\mathrm{HDL}$ - cholesterol, mg/dl & $54 \pm 5$ & $48 \pm 4$ & $52 \pm 5$ & $47 \pm 4$ \\
\hline LDL - cholesterol, mg/dl & $115 \pm 13$ & $115 \pm 18$ & $108 \pm 10$ & $118 \pm 11$ \\
\hline $\mathrm{LH}, \mathrm{mIU} / \mathrm{ml}$ & $4.9 \pm 0.4$ & $2.8 \pm 0.4^{b, f}$ & $10.7 \pm 1.2^{e}$ & $8.3 \pm 1.1^{c, d}$ \\
\hline Testosterone, ng/dl & $44.5 \pm 3.3$ & $31.4 \pm 3.9^{b . f}$ & $66.1 \pm 6.5^{e}$ & $72.6 \pm 4.7^{c}$ \\
\hline Androstendione, $\mathrm{ng} / \mathrm{ml}$ & $1.4 \pm 0.1$ & $1.8 \pm 0.1^{b, f}$ & $3.3 \pm 0.3^{e}$ & $3.5 \pm 0.2^{c}$ \\
\hline DHEA-S, $\mu \mathrm{g} / \mathrm{dl}$ & $118 \pm 13$ & $161 \pm 26^{b, f}$ & $343 \pm 41^{e}$ & $291 \pm 46^{c}$ \\
\hline Fasting glucose, mg/dl & $87 \pm 2$ & $87 \pm 4$ & $84 \pm 2$ & $88 \pm 2$ \\
\hline 2 hour glucose, $\mathrm{mg} / \mathrm{dl}$ & $113 \pm 6$ & $117 \pm 5$ & $106 \pm 8$ & $110 \pm 6$ \\
\hline Fasting insulin, $\mu \mathrm{iU} / \mathrm{ml}$ & $5.4 \pm 0.9$ & $13.9 \pm 1.7^{a f}$ & $11.4 \pm 1.3$ & $19.7 \pm 3.1^{c, d}$ \\
\hline $\mathrm{IS}_{\mathrm{OGTT}}$ & $9.4 \pm 1.0$ & $4.6 \pm 0.9^{a}$ & $4.3 \pm 0.4^{e}$ & $3.0 \pm 0.5^{c}$ \\
\hline
\end{tabular}

Values are expressed as means \pm SE. Conversion factors to SI units: Testosterone x3.467 (nmol/liter), Androstenedione x3.492 (nmol/liter), DHEA-S x0.002714 ( $\mu \mathrm{mol} /$ liter), Glucose x0.0551 (mmol/liter), Insulin x7.175 (pmol/liter). ISOGTT, Insulin sensitivity derived from the OGTT.

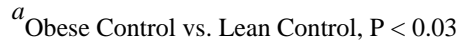

${ }^{b}$ Obese Control vs. Lean PCOS, $\mathrm{P}<0.0007$

${ }^{c}$ Obese PCOS vs. Lean Control, $\mathrm{P}<0.001$

${ }^{d}$ Obese PCOS vs. Lean PCOS, $\mathrm{P}<0.05$

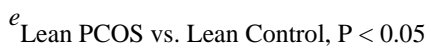

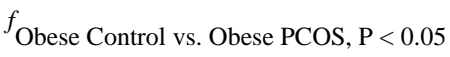




\section{TABLE 2}

Pearson correlations of cytokine release following LPS exposure or plasma IL-6 with body composition, insulin sensitivity, circulating androgens and each other for the combined groups

\begin{tabular}{|c|c|c|c|c|}
\hline & & $\begin{array}{c}\text { MNC-derived TNFa Release } \\
\text { (\% change) }\end{array}$ & $\begin{array}{l}\text { MNC-derived IL-6 } \\
\text { Release (\% change) }\end{array}$ & $\underset{(\mathbf{p g} / \mathrm{ml})}{\operatorname{Fasting~plasma~IL-6~}}$ \\
\hline \multirow{2}{*}{ BMI $\left(\mathrm{kg} / \mathrm{m}^{2}\right)$} & $\mathrm{r}$ & 0.269 & 0.222 & 0.527 \\
\hline & $\mathrm{P}$ & 0.094 & 0.180 & $0.0007^{*}$ \\
\hline \multirow[b]{2}{*}{ Waist circum $(\mathrm{cm})$} & $\mathrm{r}$ & 0.198 & 0.334 & 0.476 \\
\hline & $\mathrm{P}$ & 0.235 & $0.044^{*}$ & $0.003^{*}$ \\
\hline \multirow{2}{*}{ Total body fat (\%) } & $\mathrm{r}$ & 0.142 & 0.170 & 0.453 \\
\hline & $P$ & 0.381 & 0.308 & $0.004^{*}$ \\
\hline \multirow{2}{*}{ Truncal fat (\%) } & $\mathrm{r}$ & 0.240 & 0.185 & 0.559 \\
\hline & $P$ & 0.135 & 0.266 & $0.0003^{*}$ \\
\hline \multirow{2}{*}{ IS $_{\text {OGTT }}$} & $\mathrm{r}$ & -0.606 & -0.372 & -0.542 \\
\hline & $\mathrm{P}$ & $0.0001^{*}$ & $0.021^{*}$ & $0.0004^{*}$ \\
\hline \multirow{2}{*}{ Testosterone (ng/dl) } & $\mathrm{r}$ & 0.348 & 0.522 & 0.322 \\
\hline & $\mathrm{P}$ & $0.028^{*}$ & $0.0008^{*}$ & $0.049^{*}$ \\
\hline \multirow[b]{2}{*}{ Androstenedione (ng/ml) } & $\mathrm{r}$ & 0.567 & 0.450 & 0.371 \\
\hline & $\mathrm{P}$ & $0.0001^{*}$ & $0.005^{*}$ & $0.022^{*}$ \\
\hline \multirow{2}{*}{ DHEA-S $(\mu \mathrm{g} / \mathrm{dl})$} & $\mathrm{r}$ & 0.261 & 0.192 & 0.006 \\
\hline & $\mathrm{P}$ & 0.103 & 0.249 & 0.970 \\
\hline \multirow{2}{*}{ LPS-stimulated TNFa Release ( $\%$ change) } & $\mathrm{r}$ & --------- & 0.385 & 0.498 \\
\hline & $\mathrm{P}$ & --------- & $0.017^{*}$ & 0.002 \\
\hline \multirow{2}{*}{ LPS-stimulated IL-6 Release (\% change) } & $\mathrm{r}$ & --------- & --------- & 0.694 \\
\hline & $\mathrm{P}$ & --------- & -------- & $0.0001^{*}$ \\
\hline
\end{tabular}

LPS, lipopolysaccharide; TNFa, Tumor necrosis factor-a; IL-6, Interleukin-6; ISOGTT, Insulin sensitivity derived from Matsuda Index; r, Correlation coefficient; P, Level of significance;

* $\mathrm{P}<0.05$. 